\title{
Rose M. Bidler, Dictionnaire érotique. Ancien Français, Moyen Français, Renaissance
}

\section{Maria Colombo Timelli}

\section{(2) OpenEdition}

10 Journals

\section{Édition électronique}

URL : http://journals.openedition.org/studifrancesi/29978

DOI : $10.4000 /$ studifrancesi.29978

ISSN : 2421-5856

Éditeur

Rosenberg \& Sellier

\section{Édition imprimée}

Date de publication : 1 avril 2006

Pagination : 130-131

ISSN : 0039-2944

\section{Référence électronique}

Maria Colombo Timelli, «Rose M. Bidler, Dictionnaire érotique. Ancien Français, Moyen Français,

Renaissance », Studi Francesi [En ligne], 148 (XLX | I) | 2006, mis en ligne le 30 novembre 2015, consulté le 19 avril 2021. URL : http://journals.openedition.org/studifrancesi/29978 ; DOI : https://doi.org/ 10.4000/studifrancesi.29978

Ce document a été généré automatiquement le 19 avril 2021.

\section{(c) $($ ) $\odot$}

Studi Francesi è distribuita con Licenza Creative Commons Attribuzione - Non commerciale - Non opere derivate 4.0 Internazionale. 


\title{
Rose M. Bidler, Dictionnaire érotique. Ancien Français, Moyen Français, Renaissance
}

\author{
Maria Colombo Timelli
}

\section{RÉFÉRENCE}

ROSE M. BIDLER, Dictionnaire érotique. Ancien Français, Moyen Français, Renaissance, Montréal, CERES, 2002 («Erotica Vetera. À la recherche d'un langage perdu»), pp. 658.

1 La difficulté d'appeler les choses par leur nom en matière érotique a été de tout temps escamotée par le jeu verbal, l'allusion, la métaphore. Le Dictionnaire des locutions en moyen français de Giuseppe Di Stefano (1992), dont une nouvelle édition doit bientôt voir le jour, faisait déjà pressentir en quelque mesure la richesse de ce domaine (cf. les voix behourder, écu, lance..., et, très en général, les acceptions indiquées comme 'triv' ou 'ér'). Ce Dictionnaire érotique de Rose M. Bidler enrichit énormément la moisson; d'abord, il couvre une plus large diachronie, avec le dépouillement de textes allant du XIII à l'extrême fin $\mathrm{du} \mathrm{XVI}^{\mathrm{e}}$ siècle; ensuite, il englobe des répertoires et de nombreuses éditions récentes ayant donné accès à des textes particulièrement pertinents: on ne citera que La lune avec les dents. Dictionnaire des façons de parler du XVI siècle de Pierre Enckell (CNRS, 2000), les deux traductions du Decameron de Boccace, l'une par Laurent de Premierfait (éditée par Giuseppe Di Stefano en 1998), l'autre par Antoine Le Macon (éditée par la même Rose M. Bidler en 2002), ou encore les Pronostications joyeuses de Jean Molinet (éd. par Jelle Koopmans et Paul Verhuyck en 1998). Enfin, il porte une attention accrue à un domaine jusqu'ici peu fréquenté dans son ensemble, que les éditeurs de textes abordaient le cas échéant sans instruments spéciaux, l'insuffisance des dictionnaires de Godefroy et Huguet n'étant pas à démontrer pour certaines acceptions. 
2 La nomenclature réunie par Rose M. Bidler comprend tant des mots absolument génériques (chose, ce, ceci / cela) que des termes explicites, qui ne demandent pas d'élucidation, même si ceux-ci sont particulièrement rares (vit, cul...). Ce sont alors les emplois métaphoriques qui l'emportent très largement; on retiendra le lexique de la guerre, bien connu (arme, armure, artillerie, assaut, assaillir, bataille, behort, behourder, bouclier, canon, chateau, combat, coup, dague, écu, entrechoc, épée, escarmouche, escremie, estoc, exploit...); on se surprendra peut-être devant certains emplois du lexique religieux (Ascension, Ave Maria, Pater Noster, bénédiction, bénitier, Bible, bréviaire, cardinal, Carême, confesse, couvent, dévotion, discipline...). Mais les jeux de mots voilés sont encore possibles sur les noms de couleurs (blanc, bleu, noir...) ou sur les lettres de l'alphabet $(B, D / F, F /$ C...). Le monde de l'école est aussi mis à profit, non seulement avec les mots les plus généraux (apprenti, école / écolier, maître, écrire / écriture, encre / encrier...), mais encore avec le lexique très spécial de la grammaire. À ce propos, à côté du célèbre rondeau XIX, 4 de Charles d'Orléans, cité s.v. cas («Maistre Esienne Le Gout, nominatif, Nouvellement, par maniere optative, $\mathrm{Si}$ a voulu faire copulative; Mais failli a en son cas genitif...»), on citera la réponse du même Estienne Le Gout, certes moins réussie poétiquement, mais tout aussi significative sur le plan de l'invention langagière: «Monseigneur, tressuppellatif, Pour respondre au narratif De vostre brief-ve espositive, Elle fut premier voquative Par le moyen du genitif...».

3 Tania van Hemelryck a déjà montré comment l'ouvrage de Rose M. Bidler peut ouvrir la voie à de nouvelles recherches (Classé $X$ en moyen français... Des saints facétieux, in «Le moyen français», 50, 2002, pp. 93-114). De ma part, j'ajouterai que l'existence du Dictionnaire érotique aurait certainement facilité ma tâche lors de l'édition du Purgatoire des mauvais maris et de l'Enfer des mauvaises femmes (in Romania, 116, 1998; 119, 2001; 120, 2002), notamment pour l'établissement du glossaire; j'y aurais trouvé des mots tels que: acoint/e (intime, amant/e, maîtresse), curatiere (entremetteuse), garce (femme débauchée), gorgiasse (coquette), gouge (femme portée à la 'chose', femme de mauvaise vie), maquereau/elle (entremetteur/euse), mignonne (fille, femme de mauvaise vie), mignote (mignonne), paillarde (concubine, putain), poisson d'avril (s.v. avril: messager d'amour, entremetteur), putier (homme débauché), sorciere (cf. sorcerie: maladie vénérienne), vuihos (cf. wihot: mari trompé); le Dictionnaire n'enregistre cependant ni courtier (d'amours: entremetteur), ni entortillier (au sens figuré: séduire), ce qui montre, si besoin était, l'intérêt de certains textes 'mineurs'. Mais surtout, l'ouvrage de Rose M. Bidler m'aurait suggéré une interprétation non littérale d'un passage du Purgatoire des mauvais maris où les maris jaloux ne permettent même plus à leurs femmes de fréquenter les lieux de pèlerinage; à côté d'églises parisiennes bien connues (Sainte Geneviève, Saint Germain-des-Prés, la Sainte Chapelle, Notre Dame), est citée «Saincte Avoye»: or, la sainte était invoquée par calembour pour éviter que les maris ne se «desvoyent» (cf. les Evangiles des Quenouilles); je me demande maintenant si l'allusion à «Saincte Oportune» dans la même liste de lieux de culte ne cache pas aussi un double sens qui m'avait complètement échappé et que je ne trouve cependant pas non plus dans le Dictionnaire érotique.

4 Une ou deux suggestions pour conclure: Mme Bid-ler n'envisagerait-elle pas une publication réduite, telle que Toutes les herbes de la Saint-Jean par rapport au DLMF de Di Stefano? Serait ainsi mis à la disposition de tous les chercheurs un instrument souple, moins cher, mais dont la consultation serait tout aussi profitable. D'autre part, il serait temps, me semble-t-il, d'offrir ce genre d'instruments (et j'étends ce souhait au 
nouveau Dictionnaire des locutions en moyen français à paraittre) sous forme de CD: cela simplifierait énormément la recherche des mots et citations, sans remplacer bien entendu les beaux volumes papier traditionnels. 